Revista de la Escuela de Ciencias de la Educación. 2022, Año 18 1(17), 171188. Enero a junio. González, A. P. Discursos neuroeducacionales, diversidad y desigualdad: sobre la autoridad de la ciencia en ámbitos educativos.

\title{
DISCURSOS NEUROEDUCACIONALES, DIVERSIDAD Y DESIGUALDAD: SOBRE LA AUTORIDAD DE LA CIENCIA EN ÁMBITOS EDUCATIVOS
}

\author{
NEUROEDUCATIONAL DISCOURSES, DIVERSITY AND INEQUALITY: ABOUT THE \\ AUTHORITY OF SCIENCE IN EDUCATIONAL AREAS
}

\section{Anahi Patricia González \\ Universidad de Buenos Aires, Argentina \\ anahipgonzalez@gmail.com}

Recibido: 6 de julio de 2021

Aprobado: 12 de diciembre de 2021

Publicado: 31 de diciembre de 2021

Cita sugerida: González, A. P. (2022). Discursos neuroeducacionales, diversidad y desigualdad: sobre la autoridad de la ciencia en ámbitos educativos. Revista de la Escuela de Ciencias de la

Educación. 1(17), 171-188.

\section{RESUMEN}

El artículo tiene como objetivo analizar ciertos discursos que circulan sobre y de las neurociencias educacionales y su divulgación en los ámbitos educativos. Para ello, se resumen brevemente algunos de los debates existentes al interior de la neuroeducación como disciplina y, luego, se presentan los resultados del análisis de cursos de capacitación orientados a docentes de diversos niveles educativos en Argentina. El relevamiento del corpus de ofertas de capacitaciones y materiales didácticos ha sido efectuado en el marco de un proyecto de investigación que aborda la cuestión de los discursos neurocientíficos y sus vinculaciones con la gestión de las diversidades y desigualdades en la institución educativa. El análisis de los discursos se realizará desde un enfoque sociológico con el fin de desentrañar los posibles nodos argumentales que sustentan algunas de las propuestas que se efectúan sobre las neurociencias y su aplicación concreta en las aulas, excediendo a los objetivos del escrito evaluar la veracidad de los hallazgos que las neurociencias han obtenido como ciencia básica.

Palabras clave: Educación - Neuro-educación - Diversidad - Desigualdad Escuela. 
Revista de la Escuela de Ciencias de la Educación. 2022, Año 18 1(17), 171188. Enero a junio. González, A. P. Discursos neuroeducacionales, diversidad y desigualdad: sobre la autoridad de la ciencia en ámbitos educativos.

\begin{abstract}
The aim of this article is to analyze certain discourses that circulate on and about educational neurosciences and their dissemination in educational environments. For this purpose, some of the existing debates within neuroeducation as a discipline are briefly summarized and then the results of the analysis of training courses oriented to teachers of different educational levels in Argentina are presented. The courses and didactic materials analyzed have been systematized in the framework of the project that addresses the issue of neuroscientific discourses and their links with the management of diversities and inequalities in the educational institution. The analysis will be made from a sociological approach in order to show the possible argumentative nodes that support some of the proposals made on neurosciences and their concrete application in the classroom, exceeding the objectives of the paper to evaluate the veracity of the findings that neurosciences have obtained as a basic science.
\end{abstract}

Keywords: Education - Neuro-education - Diversity - Inequality - School.

\title{
INTRODUCCIÓN
}

"La ciencia es cómplice de todo lo que le piden que justifique"

(Bourdieu, 1978, p. 68)

En el trabajo se propone reconstruir y analizar ciertos discursos en auge de y sobre neurociencias educacionales y sus eventuales vínculos en los modos en que se piensa a los sujetos que aprenden y al mismo proceso de enseñanza y aprendizaje. Algunas de las preguntas subyacentes a este análisis son: ¿Contribuye el discurso de las neurociencias en la naturalización de las diferencias sociales y de las desigualdades? ¿De qué forma la percepción meritocrática del éxito y fracaso escolar encuentra correlatos con lo postulado por la neurociencia educacional? ¿Inciden los discursos científicos, tales como las neurociencias educacionales, en la reproducción del "racismo de la inteligencia"? ¿Ello se evidencia en algunas de las propuestas de formación docente sobre neurociencia educacional? ¿Persisten explicaciones biologicistas sobre la desigualdad en dichas propuestas?

El análisis que se realizará de los mencionados discursos será de índole sociológico con el fin de desentrañar los posibles nudos argumentales que sustentan algunas de las propuestas que se efectúan sobre las neurociencias y su aplicación concreta en las aulas. En ese sentido, no se pretende juzgar ni evaluar la veracidad de los hallazgos que las neurociencias han obtenido como ciencia básica, cuestiones que excederían al análisis que, desde categorías sociológicas, se pretende hacer en este escrito.

El artículo se organiza del siguiente modo: primero, se introducen algunos elementos del proyecto de investigación en el marco del cual se ha realizado el relevamiento de las fuentes de información a analizar. En segundo lugar, se realiza una presentación sobre ciertos debates acerca de las neurociencias educativas. Luego, se efectúa el análisis de las fuentes (cursos de capacitación y 
formación sobre neurociencias educacionales orientados a educadores/as) estructurándolo en tres dimensiones: I) Aplicacionismo de las neurociencias; II) Biologización de las diferencias: "la ideología del cerebro y de los genes"; III) "La ciencia" como autoridad incuestionada del saber legítimo.

Finalmente, en el último apartado, presentamos las principales conclusiones, líneas posibles de indagación a futuro e interrogantes que se desprenden del abordaje efectuado a lo largo del artículo.

\section{DESARROLLO}

\section{Elementos teórico- metodológicos del proyecto de investigación}

Las fuentes a analizar en este artículo han sido producidas en un proyecto de investigación que indaga sobre las representaciones sociales y diversidad en escuelas públicas en el Área Metropolitana de Buenos Aires (AMBA) ${ }^{1}$. Particularmente, en dicho proyecto, partimos de la idea de que, si bien la gestión de las relaciones interculturales dentro del espacio escolar ha sido una de las funciones que el estado nacional argentino asumió desde su conformación, la irrupción más reciente en los ámbitos escolares de discursos sobre neurociencia educativa, legitimados por el "saber científico", generan nuevas modalidades de gestión de la diversidad por parte de instancias estatales. En función de los objetivos de dicha investigación, se ha definido una estrategia de tipo cualitativa procurando identificar cuáles son las representaciones sociales subyacentes a los diseños curriculares y a las políticas públicas educativas que incluyen este tipo de discursos sobre neurociencias educacionales. Para ello proyectamos trabajar con tres fuentes: entrevistas a informantes clave (neurocientistas educacionales), grupos focales con docentes y el análisis de documentos de divulgación y ofertas y cursos de capacitación a docentes. De este cúmulo de información, hemos seleccionado para analizar en este artículo la última de las fuentes mencionadas, es decir: ofertas de capacitación a docentes y miembros de la comunidad educativa.

Como hemos explicitado en la introducción, escapa al propósito de este texto y a los objetivos de la investigación de la que se nutre, analizar las conclusiones a las que llegan los neurocientíficos, en general, y la neuroeducación, en particular, en sus experimentos y estudios de laboratorio. Nuestro interés radica en los entramados discursivos que se construyen alrededor de una serie de resultados que las neurociencias manifiestan haber comprobado en sus espacios de investigación y que luego son trasladados- muchas veces con explicaciones incorrectas, incompletas y falaces- a ofertas de formación y capacitación docente, apoyándose en el saber científico como aval principal.

En este sentido, retomando las palabras de Bourdieu nuestra mirada focaliza en "...analizar (...) las formas de legitimación del segundo orden que vienen a reforzar la legitimación escolar como discriminación legítima sin olvidar

\footnotetext{
${ }^{1}$ Proyecto UBACYT: "Diversidad migratoria y neurociencia educativa. ¿Hacia una reactualización del "racismo de la inteligencia"? Un abordaje a partir del análisis de discursos y representaciones sociales. Facultad de Ciencias Sociales - Universidad de Buenos Aires. Programación 2020-2022.
} 
los discursos de aspecto científico" (Bourdieu, 1978, p. 71) que pueden ocultar bajo el manto de la objetividad, la comprobación y el discurso legítimo y tecnocrático de la ciencia - un racismo edulcorado, encubierto pero aun así coadyuvante de la reproducción de desigualdades.

Partimos de considerar que se trata de un tema complejo, cuya investigación esperamos pueda develar modalidades contemporáneas, o que reviven antiguos debates, de vinculación de abordajes del campo biológico al análisis de problemáticas sociales.

Los docentes como agentes del Estado producen un conocimiento basado en su formación y en el sentido común históricamente construido acerca del proceso de enseñanza-aprendizaje, de cuál es el rol de la escuela y de los actores principales que conforman la comunidad educativa. El conocimiento cotidiano sobre cómo se enseña y aprende, está distribuido socialmente, al tiempo que, cada docente tiene un saber acerca de los procesos de aprendizajes y de sus alumnos/as, que puede variar en su grado de nitidez y claridad, ya sea porque es producto del trato directo, de la mera creencia, de sus procesos formativos, etc. Las ofertas de capacitación que analizaremos en este escrito, se ven influenciadas por un discurso refrendado por el prestigio de la ciencia. De este modo, la legitimidad de este discurso se arraiga en las representaciones que ya circulan entre los educadores sobre la validez de un enfoque cuyo prestigio se asienta en la ciencia, la cual -como sostiene Bourdieu (1978) en su texto "El racismo de la inteligencia"- puede actuar como una forma de justificación de clasificaciones y discriminaciones en el espacio escolar. De manera que, sin detrimento de que los docentes puedan asumir una postura crítica sobre el discurso neurocientífico, nos interesa abordar en este artículo qué es lo que se les ofrece como formación a los maestros/as y profesores/as en relación a las neurociencias educacionales, qué herramientas para sus prácticas de enseñanza, qué rol se le da a la escuela, a los propios docentes, a sus conocimientos y expertisse.

\section{Debates acerca de las neurociencias educativas}

La cuestión de los procesos de enseñanza y aprendizaje, del rol de las instituciones educativas y la formación de los maestros y maestras, profesores y profesoras implica múltiples y arduas discusiones. Es decir, la educación suscita el interés de muchos sectores propios de la comunidad educativa y externa a la misma. En dicha miríada de debates, los discursos neuro-científicos han encontrado también su modo de proponer sus postulados, con el objeto de insertar, articular, oponer y/o complementar otras perspectivas que podríamos denominar "clásicas", provenientes de las ciencias sociales o humanísticas (estamos hablando de ciencias de la educación, sociología, antropología, etc.).

Una primera definición que podemos dar acerca de la neuroeducación es que se trata de la "(...) introducción del estudio neurocientífico del cerebro en los procesos de aprendizaje y su posible aportación a la enseñanza" (PallarésDomínguez, 2016, p.941).

En ese sentido, cabe preguntarse: ¿cuáles son los sentidos que se construyen en relación al tema de la educación en los discursos de la neurociencia educacional? ¿Qué matices podemos encontrar al interior de esos discursos y de 
Revista de la Escuela de Ciencias de la Educación. 2022, Año 18 1(17), 171188. Enero a junio. González, A. P. Discursos neuroeducacionales, diversidad y desigualdad: sobre la autoridad de la ciencia en ámbitos educativos.

sus debates? Hacia mediados del siglo pasado podemos identificar los primeros intentos por vincular a las neurociencias con la educación, no obstante, los debates contemporáneos -en los que abrevan las ideas que hoy en día circulan en el campo educativo- pueden rastrearse en la década de 1990, en lo que Pallarés-Dominguez (2016) considera como la "década del cerebro". La literatura identifica tres acontecimientos que marcan un antes y un después en el enlace entre neurociencia y educación (Lipina, 2016). El primero de ellos ocurre en 1996. Se trata de un encuentro organizado por la Comisión de Educación de los Estados y la Fundación Dana en la cual diversos especialistas del área (neurocientíficos, psicólogos cognitivos, educadores e investigadores en educación y diseñadores de políticas públicas) compartieron sus investigaciones, ideas y conclusiones sobre neurociencia cognitiva y psicología cognitiva vinculada a la educación. Al finalizar el congreso,

(...) los participantes generaron un documento con diferentes recomendaciones comunicacionales y para el diseño de políticas educativas en el futuro; (...) con el objetivo de alcanzar a los medios de comunicación, al público en general y a los diseñadores de políticas educativas (Lipina, 2016, p.7).

Como puede evidenciarse, este encuentro no solo tuvo objetivos vinculados a la investigación básica, sino que subyacía la pretensión de difundir en la comunidad educativa y en el público en general las conclusiones a las que se habían llegado, intentando desarrollar estrategias de comunicación para la divulgación de estas ideas y su eventual aplicación en políticas públicas educativas y transferencias de resultados de las investigaciones a la práctica educativa.

Los otros dos acontecimientos de la misma década que, siguiendo a Lipina (2016), pueden señalarse en el fortalecimiento del lazo entre neurociencia y educación son dos papers de referencia en el campo: Education and the Brain: $A$ bridge too far, escrito por Bruer y publicado en 1997 y The Educational relevance of research in cognitive neuroscience, cuya autoría corresponde a Byrnes y Fox y que fuera publicado en 1998.

Ambos textos no establecían aplicaciones concretas para la enseñanza en el aula, sino que planteaban la relevancia de continuar las investigaciones sobre las potencialidades que presentaban, desde su perspectiva, el análisis neural y los hallazgos de las pesquisas sobre neurociencia cognitiva como modo de enriquecer las prácticas educativas. Del trabajo de Bruer, interesa rescatar que se hace mención a algunos conceptos, presentes en los discursos sobre neurociencia educacional y muchas veces erróneamente utilizados hoy en día, tales como periodos críticos, enriquecimiento ambiental (ambos hacían referencia a conclusiones de investigaciones efectuadas en laboratorios y en relación al cerebroo de roedores), desarrollo infantil temprano, entre otros.

Posteriormente, se extenderán a nivel internacional, sobre todo en países centrales, programas de investigación en múltiples universidades, estudios de posgrado, escuelas de neurociencias y nuevas publicaciones especializadas. En fin, un novedoso y fructífero campo de estudio comenzaría a consolidarse hasta llegar hoy día. Actualmente, podemos ver una gran variedad de propuestas en 
las cuales se detecta un gradiente que incluye desde líneas de investigación que mantienen las precauciones que sus propios referentes, como Bruer, señalaban acerca de las dificultades y peligros de "saltar" del laboratorio al aula y otras que han aplicado "propuestas espúreas sobre el uso del conocimiento neurocientífico en contextos educativos" (Lipina, 2016, p.7).

En aquel texto de 1996, Bruer advertía sobre el puente aún muy lejano entre los aportes que traían las neurociencias y su aplicación en el aula con estudiantes reales. También prevenía sobre las concepciones "neuro" erróneas que pudieran penetrar en los diseños curriculares. Luego de varias décadas de aquella publicación Bruer (2016) continúa sosteniendo que la neurociencia educativa es una ciencia básica que puede contribuir al desarrollo del conocimiento básico en educación pero que no necesariamente sus hallazgos puedan ser trasladados de modo directo a la enseñanza en el aula.

Hoy día, la multiplicidad de enfoques hace que ya no se hable de neurociencia sino de neurociencias en plural. Ello denota la proliferación de perspectivas que retoman, en mayor o menor grado, los antecedentes que hemos señalado anteriormente. Podemos resumir, no sin riesgo de simplificar el asunto en demasía, las reacciones a los diversos modos de interpretación de los aportes y peligros de esta disciplina en las siguientes posturas críticas: aquellas que sostienen un rechazo absoluto de las propuestas de las neurociencias educacionales sobre todo por el uso inadecuado y simplista de postulados de la ciencia neuronal en el ámbito educativo, que termina ofreciendo recetas a aplicarse en el diseño curricular y de políticas públicas con un marcado tinte biologicista y medicalizante (Carli, s/f; Merlin, 2017; Kaplan, s/f); otras opiniones que advierten que las conclusiones a las que llegan las investigaciones básicas de las neurociencias educacionales no pueden ser concluyentes advirtiendo sobre los riesgos de los "neuromitos" y de la "validez ecológica baja" de los postulados de esta disciplina (Terigi, 2016; Castorina, 2016) y otras que sostienen que sus postulados, por el momento, no pueden ser aplicados a propuestas de enseñanza concretas aunque presentarían ciertas potencialidades si se trabaja de modo interdisciplinario (Pallares Domínguez, 2016; Lipina, 2016; Benarós, et.al., 2010). En esa línea, se enfatiza en el trabajo interdisciplinario con otros campos como estrategia para el desarrollo y la aplicación de la neurociencia educativa, sobre todo con aquellas ciencias que tienen como punto de partida "la mente, en lugar del cerebro", tales como la psicología cognitiva. (Marcus, 2013). También existen las posturas de autores como Bowers (2016) y De Vos (2016), quienes sostienen que lo que algunas corrientes de las neurociencias pretenden aportar a la práctica de docente son, en su mayoría, autoevidentes. Por ejemplo, plantear que las dificultades de aprendizaje se vinculan con entornos estresantes o con malos hábitos de sueño son conclusiones a las que ya habían arribado otras disciplinas. Asimismo, dicen que la aparente colaboración que supuestamente aportan, podría ocasionar a los educadores más problemas que soluciones.

Castorina (2016) examina aspectos filosóficos y de sentido que la neurociencia educativa supone, recuperando los debates acerca de su aplicabilidad. Así, sostiene que el estudio de la actividad del cerebro es condición necesaria pero no suficiente para comprender acabadamente los procesos de aprendizaje, siendo importante asumir un enfoque interdisciplinario como uno de 
los aspectos centrales. Este autor además coloca su atención en la confusión conceptual que remite a que el cerebro humano crea significados, aprende, entiende, adjudicándole a un órgano en y por sí mismo una serie de capacidades pudiéndose focalizar en aquel para "solucionar" los obstáculos de los procesos de enseñanza y aprendizaje.

En Latinoamérica, en general, y en Argentina, en particular, podemos evidenciar una creciente propagación de discursos referentes a la neurociencia, la educación y su aplicación en la práctica docente (Ferreres y Abusame, 2016; Battro, 2011; Battro y Cardinali, 1996; Manes, 2013) que se refleja también en la proliferación de ofertas de capacitación, seminarios y cursos orientados a profesores/as, maestros/as y formadores en general pero en las cuales, si bien puede aparecer el término interdisciplinar- sobre todo en el speech de oferta del curso, ello no pareciera traducirse en los contenidos y las modalidades unidireccionales en que se desarrollan los encuentros con los maestros y profesores.

También debemos considerar, en cuanto a la divulgación, lo que Terigi define como contextos de difusión y de enunciación de las neurociencias educacionales. Al respecto, la autora refiere que, en Argentina, por ejemplo, "se encuentra en revisión la centralidad del Estado en la política educativa y se pone en cuestión la idoneidad de maestros y profesores para llevar adelante la tarea de enseñar" (2016, p.59). En ese escenario, el riesgo se configura en la posibilidad de la oferta de soluciones simplistas, "paquetes" de tecnologías y recetas (todo un mercado de producciones en que los contenidos se centran en lo "neuro") que no consideran las múltiples aristas que implican los procesos de aprendizaje, así como la aplicación descontextualizada de técnicas de enseñanza que dejen de lado al sujeto que aprende, focalizándose en "el cerebro". En suma, como lo plantea Terigi "una parte de la discusión se centra en el posible retorno del determinismo biológico y su relación con retrocesos políticos en el reconocimiento de la igualdad" (2016, p.60). Volveremos sobre este aspecto en el próximo apartado, cuando analicemos las ofertas de cursos de capacitación para educadores.

Por último, debemos resaltar que una de las principales advertencias en relación al aplicacionismo de las neurociencias educativas remiten a los denominados "neuromitos" (Pallarés Domínguez, 2016; OCDE, 2007). En consonancia con ello, por ejemplo, el trabajo de Dekker, et.al. (2012) reúne los resultados de una encuesta- realizada a 242 profesores de escuelas primarias y secundarias en una serie de regiones de Reino Unido y de los Países Bajos - sobre las neurociencias aplicadas a la educación. Entre sus hallazgos, identificaron que el $49 \%$ de los neuromitos fueron corroborados. Sus conclusiones refieren a que los docentes, entusiastas de la aplicación de las neurociencias a la educación no lograban distinguir con facilidad entre pseudociencia y hechos científicos.

En la sección siguiente realizaremos un análisis de propuestas y ofertas de capacitación a docentes en Argentina con el objetivo de evidenciar algunos de estos "neuromitos", así como otros aspectos a problematizar en relación a las neurociencias educacionales. 
Revista de la Escuela de Ciencias de la Educación. 2022, Año 18 1(17), 171188. Enero a junio. González, A. P. Discursos neuroeducacionales, diversidad y desigualdad: sobre la autoridad de la ciencia en ámbitos educativos.

\section{Neurociencia educacional y las tensiones con la diversidad y desigualdad en el aula}

Cuando se aborda la cuestión de los procesos de enseñanza-aprendizaje desde las ciencias sociales podemos citar una variedad de trabajos que refieren a la importancia de contextualizar a los sujetos que aprenden. Desde enfoques clásicos en la sociología como los de Bourdieu (1997) hasta investigaciones contemporáneas de las últimas décadas, particularmente en Argentina las generadas por Duschatzky y Skliar (2000); Gagliano (1991); Jordán (1994); Diez, et.al. (2017); Tenti Fanfani (2007); Kaplan (1997); entre muchos otros/as, focalizan su atención en el rol de las instituciones educativas como productoras y reproductoras de sentidos sobre los estudiantes y sus trayectorias formativas. En relación a las neurociencias educativas, un aspecto de este campo remite a "(...) la formación de docentes e investigadores en conceptos y metodologías propios de las disciplinas de neurociencia y educación" (Lipina, 2016, p. 11). En sintonía con ello, uno de los puntos de mayor debate se centra en las consecuencias que podría acarrear el hecho de que sus postulados sean llevados de modo mecánico a la "práctica educativa". Sobre este tema nos interesa ahondar en las páginas que siguen.

Con ese objetivo plantearemos una serie de dimensiones de análisis que se han podido identificar en el rastreo y lectura de ofertas de capacitación y formación de docentes sobre neurociencias educacionales relevados en el marco de la investigación a la que ya hemos hecho referencia. El propósito no es focalizar el análisis en un caso en particular, sino identificar cuáles son los discursos que circulan en ámbitos de formación y cursos de capacitación sobre neurociencias educacionales orientados a docentes de diversos niveles educativos. Nuestro interés está en la identificación de una serie de nodos discursivos, en los sentidos que construyen y en las eventuales consecuencias que pudieran tener en la construcción de representaciones sociales que entiendan de modo descontextualizado los procesos de enseñanza-aprendizaje y expliquen las diferencias en el aprendizaje de los estudiantes como deficiencias a partir de argumentos biologicistas sustentados en la autoridad de "la ciencia".

Para este apartado se han seleccionado tres dimensiones o nodos discursivos de interés a analizar: I) Aplicacionismo de las neurociencias; II) Biologización de las diferencias: "la ideología del cerebro y de los genes" "; III) "La ciencia" como autoridad incuestionada del saber legítimo.

\section{I) Aplicacionismo de las neurociencias}

Con este término nos referimos a una de las preocupaciones $y / 0$ intereses principales (según el caso) que han tenido quienes investigan en el área de la neurociencia educacional En pocas palabras, el pasaje del laboratorio (espacio en el que se pueden controlar las variables experimentales) al aula (con sus complejidades, contradicciones y contingencias propias del mundo social), lo cual

\footnotetext{
${ }^{2}$ Expresión tomada del texto Kaplan, C. (s/f) Papeles de coyuntura 2. Programa de Investigación Escolarización. Perspectivas históricas, pedagógicas y políticas de la educación. Instituto de Investigaciones en Humanidades y Ciencias Sociales, UNLP. Recuperado el 15 de octubre de 2020 de: http://idihcs.fahce.unlp.edu.ar/pephpp/wp-content/uploads/sites/25/2019/10/2-papeles-decoyuntura-emociones-y-escuela.pdf
} 
Revista de la Escuela de Ciencias de la Educación. 2022, Año 18 1(17), 171188. Enero a junio. González, A. P. Discursos neuroeducacionales, diversidad y desigualdad: sobre la autoridad de la ciencia en ámbitos educativos.

se traduce en acciones de diversos grados que abarcan desde lineamientos de políticas educativas (planes, programas, planificaciones, capacitaciones orientadas a docentes, etc.) hasta acciones pedagógicas concretas.

Específicamente, el aplicacionismo, en el caso de las neurociencias educacionales, supone:

... la pretensión de derivar de las neurociencias directrices para la práctica pedagógica u orientaciones de política educativa. (...)" y, ello "(...) no es algo que pueda convalidarse con el actual conocimiento del que se dispone y tampoco es algo que pueda llegar a ser enteramente pertinente para la práctica educativa si la investigación no gana en validez ecológica (Terigi, 2016, p.60).

Con validez ecológica Terigi refiere a los grados en que lo que se estudia bajo la condición controlada de una experiencia de laboratorio se asemeja a lo que sucede en el escenario real, por ejemplo, el proceso de aprendizaje de la lectura en la escuela. En este sentido, la primera información que puede señalarse del análisis cualitativo efectuado de los cursos y capacitaciones sobre neurociencias es que no parecieran contemplarse las advertencias acerca de dicha validez. Un indicador de ello es la presencia de frases (muchas de ellas en los títulos que publicitan los encuentros, clases o charlas) como las siguientes:

\footnotetext{
"Neurociencia y educación: la evidencia científica en el aula."

"Crear un aula con cerebro, entornos compatibles al cerebro".

"El principal objetivo del laboratorio será el de trasladar al pie del aula numerosas teorías educativas con bases científicas y neurocientíficas".

"Educar con el cerebro en mente. Estrategias y conocimientos de las neurociencias para el aula".

"Neurociencias en el aula"

"Paso a paso, el cerebro en el aula"
}

Como se evidencia en las frases tomadas a modo de ejemplo, la referencia a la aplicación en el aula de los resultados y hallazgos de investigaciones de la neurociencia se hace evidente. Las advertencias de muchos neurocientíficos, por ejemplo, Bruer ${ }^{3}$, quien fuera señalado como uno de sus principales iniciadores, no son consideradas en gran parte de este tipo de dispositivos de formación de maestros y maestras, profesoras y profesores, entre otros eventuales interesados. Inclusive, en algunas de las publicidades aparece la leyenda: "Neurociencias aplicadas a la educación" o "Introducción general a las neurociencias aplicadas a la educación"; "conocer el funcionamiento del cerebro a través de los descubrimientos en Neurociencias con énfasis en capacitación

\footnotetext{
${ }^{3}$ Bruer (2016) sostiene que la neurociencia educativa no es todavía una ciencia aplicada, sino una ciencia básica que puede contribuir a la investigación básica en educación, pero no necesariamente en forma directa a la enseñanza en el aula.
} 
Revista de la Escuela de Ciencias de la Educación. 2022, Año 18 1(17), 171188. Enero a junio. González, A. P. Discursos neuroeducacionales, diversidad y desigualdad: sobre la autoridad de la ciencia en ámbitos educativos.

práctica y activa para aplicación directa". Así se expresa esta tendencia en la convocatoria de unas jornadas sobre la materia:

Actualmente las escuelas necesitan que abramos las puertas del aula a las neurociencias y neuroaprendizaje y comencemos a descubrir cómo aprende el órgano del aprendizaje: el cerebro (Jornadas sobre Neuroeducación, Familia y Escuela, realizada en octubre de 2020).

Una de las primeras reflexiones que, desde el punto sociológico, podemos hacer al respecto es que este aplicacionismo puede repercutir en una mirada en la que prime la descontextualización del proceso de enseñanza-aprendizaje y del diseño y aplicación de políticas públicas educativas. Esa mirada que focaliza en una parte, en la evaluación del proceso de enseñanza y aprendizaje a partir de la observación de indicadores "objetivos", se asemeja la mirada del médico clínico que describía Foucault (2004, p.173), aquel " agente separador de las verdades", basado en el análisis de observables, en el análisis de lo que experimenta el cerebro y que, por ejemplo, encuentran sus correlatos en los modos de evaluar el aprendizaje de los estudiantes a través de pruebas estandarizadas que no consideran los contextos ni las particularidades en que aquellas y aquellos se encuentran.

Este enfoque del análisis neural es ayudado por los desarrollos- sin duda fundamentales en materia de diagnóstico de determinadas patologías asociadas al cerebro- de las técnicas de neuroimágenes, tales como resonancia magnética $(\mathrm{RM})$, imagen por tensor de difusión, tomografías por emisión de positrones (TEP, PET), entre muchas otras.

Es decir, indicadores de aprendizaje basados en la "actividad cerebral" que pueden identificarse sin que el sujeto que aprende se exprese, reduciendo su complejidad a mecanismos neurales. Cabe preguntarse aquí entonces: ¿Qué lugar se le da a la enunciación discursiva de los estudiantes en sus diversidades subjetivas? ¿y a sus contextos sociales y económicos?

\section{II) Biologización de las diferencias: "la ideología del cerebro y de los genes"} Uno de los conceptos que se reiteran en los cursos analizados es el término neuro y cerebro. El cerebro adquiere una centralidad suprema, adjudicándosele en repetidas oportunidades características subjetivas. Así, frases tales como "el cerebro que aprende"; "qué necesita y cómo aprende nuestro cerebro"; "qué necesita nuestro cerebro para aprender"; "evitar estudiantes dominados por el cerebro reptil y mamífero para lograr tenerlos en su cerebro racional"; "crear ambientes donde nuestro cerebro tenga el deseo de quedarse", revelan la traducción de una serie de representaciones sociales propias del ámbito científico a representaciones del sentido común que hacen que se considere que "es el cerebro el que ama, aprende, fracasa" (Kaplan, s/f, p.3).

De manera que, si bien la persona que aprende aparece por momentos en el discurso, el "cerebro" posee un lugar central en los enunciados y explicaciones sobre el aprender y las tácticas a desarrollar por los docentes para enseñar. La

\footnotetext{
${ }^{4}$ Se retoma esta frase utilizada por Kaplan (s/f) en el escrito ya citado.
} 
Revista de la Escuela de Ciencias de la Educación. 2022, Año 18 1(17), 171188. Enero a junio. González, A. P. Discursos neuroeducacionales, diversidad y desigualdad: sobre la autoridad de la ciencia en ámbitos educativos.

mención de las preocupaciones por "la neuroplasticidad", "los sellos neocorticales", "las densidades sinápticas", refuerzan la validez del discurso postulado que, dada la terminología técnica, es recibida por los receptores del mensaje, en este caso educadores, como un discurso avalado por la ciencia y, consecuentemente, nada generaría la sospecha de que se trate de falsedades que precisen ser evaluadas en su veracidad.

Si analizamos estos discursos y la creación de sentidos que suponen, podemos pensar que en la centralidad del cerebro y de lo neuro se reactualiza aquella idea de Foucault del cuerpo como realidad "biopolítica" que implica gestión de vida, creación de sujetos y subjetividades. En ese sentido, ese reemplazo del sujeto-persona en las oraciones por el sujeto-cerebro no debe hacernos olvidar que se trata igualmente de modalidades de gestión de las relaciones ente sujetos y no "entre cerebros". Es decir, como suele suceder, cuando se analizan los discursos intentando identificar las relaciones de poder y dominación subyacentes, aquello no dicho puede ser lo central a analizar.

Consecuentemente, cabe interrogarse sobre este tipo de gestión que asume un lenguaje científico y que se presenta como abierto al diálogo interdisciplinario y advirtiendo sobre sus limitaciones para dar recetas a los docentes en el ejercicio de su labor pero que, en la práctica, al menos ello puede identificarse en los discursos presentes en las fuentes analizadas aquí, proponen una visión fundada primordialmente en los hallazgos neurocientíficos alcanzados a nivel de la investigación básica. Al respecto coincidimos con Kaplan (s/f, p.3) al decir que "nadie puede poner en duda las importantes contribuciones científicas de las neurociencias. Sin embargo, sí se puede poner en cuestión ciertos usos mercantilizados de sus conceptos" y su arraigo en una mirada positivista.

El poder soberano de la mirada empírica de la que habla Foucault (2004, p.7), en su obra "El nacimiento de la Clínica...", se reactualiza en el fanatismo por el estudio del cerebro, de las células del sistema nervioso; todo ello con el uso novedoso de técnicas como la resonancia magnética funcional y el electroencefalograma, entre otras que permitirían identificar ciertos procesos que actúan en los procesos de enseñanza y aprendizaje y que serían útiles para la práctica docente.

Sobre este punto, podemos hacer una analogía con lo que Foucault describe en su obra precedentemente citada, sobre la nueva estructura que la medicina consolida - como ciencia que se ocupa de curar la enfermedad- al sustituir la pregunta con la que se iniciaba el diálogo en la consulta entre paciente y doctor en el siglo XVIII: ¿Qué tiene usted? por aquella propia de la clínica: ¿Dónde le duele a usted? Es así que "la medicina de los síntomas" se disipa ante la "medicina de los órganos", de la medicina de la anatomía.

Algunos de los elementos de esta caracterización de la mirada clínica que efectúa Foucault pueden identificarse en el discurso de las neurociencias educativas, en su versión de divulgación para educadores como la que estamos analizando aquí. Las nuevas técnicas que posibilitan "visibilizar", "ver" al cerebro, habilitan que "lo que era fundamentalmente invisible se ofrezca a la mirada", de este modo, "los límites de lo visible y lo invisible siguen un nuevo trazo" (Foucault, 2004, p.275) 
"Clases cerebralmente amigables para que sus alumnos recuerden lo que usted les enseña", se propone en una capacitación a docentes, o enunciados discursivos como que "el cerebro presta atención a lo que considera relevante para la vida y llega más fácilmente a convertirse en memoria de largo plazo", evidencian la intención de emplear recursos de las neurociencias educacionales para desarrollar estrategias para enseñar. Resulta significativa, la alusión al cerebro como sifuera un sujeto que desplaza a los y las estudiantes, conllevando además una serie de representaciones sociales que des-historizan y descontextualizan el proceso de enseñanza y aprendizaje. En este sentido, reorientar la centralidad de la enseñanza a cuestiones biológicas, de funcionamiento de un órgano implica al menos repensar cuál es el lugar que tienen en estas propuestas las dimensiones sociales y la práctica de enseñanza como relación social.

De este modo, arraigado en el hecho de que en las investigaciones neurocientíficas es el cerebro la unidad de análisis u objeto de estudio, los hallazgos sobre este órgano llegan al ámbito educativo, en muchas de las propuestas analizadas, de modo simplista y en varias ocasiones como ideas erróneas o neuromitos que refuerzan representaciones sociales ligadas a un enfoque determinista biologizante. Kaplan ( $\mathrm{s} / \mathrm{f}, \mathrm{p}$. 3 ) advierte que estas perspectivas no debieran ser interpretadas inocentemente y retoma algunas de las ideas del biólogo Stephen Gould (1997) quien plantea que históricamente:

(...) las argumentaciones reduccionistas biologicistas, centradas en las características genéticas de los individuos, se correlacionan con episodios de retroceso político, en especial con las campañas para reducir el gasto del Estado en los programas sociales (...) Precisamente, la ideología del cerebro y de los genes refuerza el efecto cuna al escindir el orden biológico del orden sociocultural; por lo cual responsabiliza a los individuos por sus batallas ganadas o perdidas (Gould, 1997, s/r).

Va de suyo- y parte de ello hemos referido en páginas previas- que al interior del campo de quienes trabajan la temática de neurociencias educacionales existen matices y posturas más o menos proclives a la aplicación de sus hallazgos en la práctica de la enseñanza. En ese contexto, una de las advertencias que realizan diversos especialistas es a la generación, reproducción y persistencia de ciertos neuromitos. Es importante mencionar algunos de lo que identificamos en las propuestas de capacitación analizadas y que asumen algún grado de biologización de las diferencias:

- Que las personas aprenden mejor cuando reciben información en su estilo de aprendizaje preferido (por ejemplo, auditivo, visual, cinestésico).

- El señalamiento del dominio hemisférico (cerebro izquierdo, cerebro derecho) como indicador que puede explicar las diferencias en el aprendizaje de los/las estudiantes.

- Que hay períodos críticos en los niños/as después de los cuales no pueden aprender ciertos contenidos o destrezas.

- Que solo usamos una parte de nuestro cerebro. 
Revista de la Escuela de Ciencias de la Educación. 2022, Año 18 1(17), 171188. Enero a junio. González, A. P. Discursos neuroeducacionales, diversidad y desigualdad: sobre la autoridad de la ciencia en ámbitos educativos.

-Que existe una tipología de cerebros compuesta por: cerebro racional o humano, cerebro emocional o mamífero y el cerebro instintivo o reptiliano.

Estos son tan solo algunos ejemplos de neuromitos que rastreamos y registramos en los enunciados discursivos de las fuentes relevadas. Estos discursos y representaciones se basan en una mirada cargada de sentidos que se sedimenta y sostiene en la legitimidad del conocimiento científico. Algunas reflexiones al respecto, nos interesa compartir en la próxima sección.

\section{III) "La ciencia" como autoridad incuestionada del saber legítimo.}

En los materiales didácticos analizados hemos podido encontrar que los contenidos que se trabajan son introducidos al lector o lectora con enunciados tales como: "desde la ciencia está comprobado...", "la ciencia ha probado que..." "el avance científico en neurociencia evidencia que...". En este sentido, el hecho de recurrir a la autoridad legítima de la ciencia como aval es evidente.

Retomemos la idea de la mirada positivista, a la que hemos hecho referencia al introducir el enfoque foucaultiano al análisis. El positivismo, en general como enfoque epistémico y filosófico, se basaba "... en los poderes originarios de lo percibido y su correlación con el lenguaje, (...) la estructura secretamente lingüística de lo dado..." (Foucault, 2004, p. 279)

Es así que, en variadas propuestas de formación para docentes, se recurre a argumentos ligados a la cientificidad y objetividad de los aportes potenciales de las neurociencias educacionales para la tarea de enseñar. Insistimos que no es la pretensión de este artículo negar ni cuestionar los avances que desde las neurociencias se han hecho para la compresión y mejora de condiciones como la dislexia, la discalculia u otros tipos de situaciones o condiciones, sino problematizar los usos discursivos que se han dado, en ciertas oportunidades, de los hallazgos de esta disciplina.

Así, podemos identificar en el siguiente fragmento de convocatoria a una capacitación para docentes la presencia de este tipo de entramado discursivo que apela al prestigio de la ciencia y la posibilidad de su "bajada práctica" al aula.

Los continuos avances en el conocimiento del funcionamiento del cerebro nos permiten vislumbrar factores claves a tener en cuenta en nuestras aulas para promover el aprendizaje y las competencias necesarias para el mundo desafiante en el cual vivimos. A través de una aplicación y bajada práctica, el curso invita a todos los docentes, profesores, estudiantes y profesionales vinculados a la educación y capacitación a formar parte de un nuevo paradigma educativo... (Jornada Internacional de Neurociencias y Educación, Fundación Educar, 2019)

En suma, los discursos se presentan siempre con el aval de la autoridad de la evidencia científica (Ver imagen $\mathrm{N}^{\circ} 1$ ). Otras enunciaciones plantean la necesidad imperiosa de la capacitación en neurociencias, dado que la terminología técnica no puede aprehenderse de otro modo y es necesaria para "llevar la neurociencia a la clase" y mejorar los procesos de enseñanza. Solo adquiriendo estos conocimientos previos es posible comprender acabadamente los descubrimientos neurocientíficos y su posterior aplicación. Podríamos ensayar aquí la idea de que se trata del ejercicio de una violencia simbólica de unas 
ciencias sobre otras, de una jerarquización de disciplinas. En este escenario cabe interrogarse: ¿Es factible la interdisciplinariedad que propugnan neurocientíficos divulgadores de estas ideas en centros de capacitación, jornadas de formación, charlas y talleres como los analizados aquí? Más concretamente: ¿Es posible un intercambio con real igualdad de los saberes que portan los maestros y maestras (fruto de su formación y su práctica profesional) y la que introducen los "neurocientistas" de la educación?

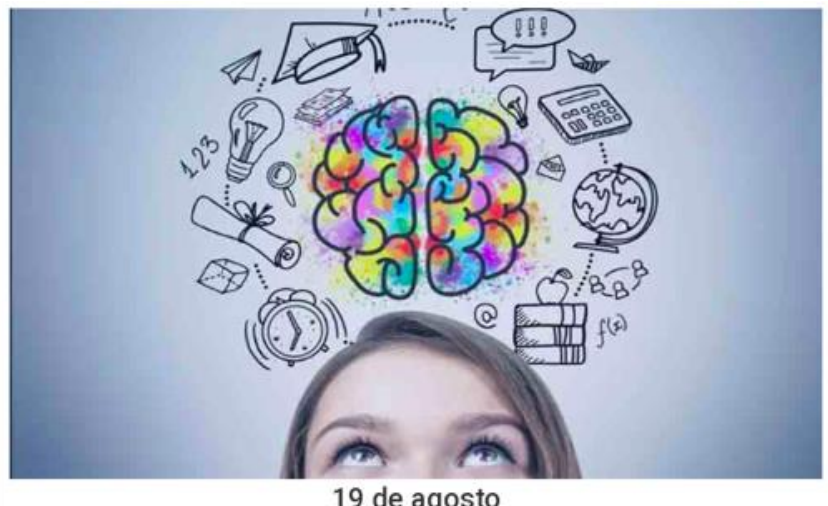

19 de agosto

Neurociencias y educación. La evidencia científica en el aulaEn el curso de esta actividad conocerás los fundamentos científicos que las neurociencias ofrecen para pensar la educación actual v la del futuro

Imagen No 1 Posteo en la red social Facebook de curso sobre neurociencia y educación. Fuente: Fundación INECO.

Consultado en julio de 2019, de https://www.facebook.com/INECOArgentina

Asimismo, esta violencia simbólica se traslada también a la relación docente-alumno/a. Es menester recordar que para Bourdieu la violencia simbólica no es una violencia "espiritual" sin efectos reales, sino una violencia que es imprescindible para la perpetuación de las relaciones de dominación. En este sentido, las estructuras de dominación "... son el producto de un trabajo continuo (histórico, por tanto) de reproducción al que contribuyen unos agentes singulares (...) y unas instituciones: Familia, Iglesia, Escuela, Estado" (2000, p.50).

Hay que decir que el aspecto disciplinador y normalizador de la Escuela no resulta novedoso, ciertamente desde los comienzos de la construcción del sistema educativo nacional argentino, por ejemplo, el Estado consideró a las instituciones educativas como espacios generadores de ciudadanos/as que debían aprender pautas de comportamiento cívico, de trabajo y culturales propios de los procesos de nacionalización de la sociedad y constitución del sistema productivo capitalista. En dicho propósito, la inclusión- entendida como la tarea de capacitar a todos los habitantes del territorio a través de la Escuela Común y posteriormente también la formación de la nacionalidad (Bertoni, 2007)- no tendría espacio para la singularidad y la diversidad (por ejemplo, de los migrantes con sus idiomas de origen como los italianos o las comunidades originarias, con sus particularidades culturales) que serían subsumidas por el efecto homogeneizante de una cultura y una nación. 
Contemporáneamente, los debates sobre educación se ven atravesados por un paradigma que no puede soslayar perspectivas tales como el enfoque de género, de derechos humanos, de interculturalidad y el interseccional, etc. No obstante, como hemos dicho, los discursos de las neurociencias educacionales son presentadas como posibles soluciones a problemáticas reales que afectan a las escuelas y los educadores: la deserción escolar, las dificultades de aprendizaje de sectores excluidos y empobrecidos, los recortes presupuestarios en el área de la educación, las brechas digitales, entre muchos otros fenómenos. En ese escenario, los discursos neurocientíficos también, divulgados en capacitaciones como las analizadas, construyen y reproducen determinadas representaciones sociales sobre los y las estudiantes y lo hacen- plasmando sus ideas en planes y programas educativos y en capacitaciones a educadores en un espacio fundamental de socialización como lo son las escuelas del Estado, sean estas de gestión privada o estatal.

Ciertas ideas divulgadas en las capacitaciones analizadas, se vinculan con la idea meritocrática del esfuerzo individual que redituará en el éxito en este caso académico, descontextualizado de las reales y desiguales oportunidades que atraviesan a muchos estudiantes en lugares como Argentina y gran parte de la región. Al respecto, recuperamos el concepto de "racismo de la inteligencia" de Bourdieu que "... es la forma de sociodicea característica de una clase dominante cuyo poder reposa en parte sobre la posesión de títulos que, como los títulos académicos, son supuestas garantías de inteligencia" (Bourdieu, 1978, p.67) permiten entender un racismo diferente, no ya el racismo biologicista clásico, que en la era de la interculturalidad, resulta censurable en sus formas más directas, sino un racismo insinuado, indirecto. En el caso que estamos abordando aquí el prestigio y la autoridad legítima de la ciencia es interpelada para construir sentidos sobre un asunto que ha sido de interés del Estado desde sus comienzos: la educación. De este modo, sean propuestas públicas o privadas las que ofrecen las capacitaciones, todas las que se han analizado aquí refieren a una cuestión social que se haya vinculada fuertemente con la capacidad que tiene el estado de infundir categorizaciones, calificaciones y clasificaciones, trazar delimitaciones y reproducir realidad social.

\section{CONCLUSIÓN}

Este artículo pretendió proporcionar algunos elementos para analizar un discurso particular acerca de la educación y los procesos de enseñanza y aprendizaje: el de las neurociencias educacionales.

Como se ha dicho en varias oportunidades no se pretende cuestionar los hallazgos que a nivel de ciencia básica ha podido obtener la neurociencia, sino problematizar las representaciones sociales que se producen en torno a los usos de aquellos resultados en el espacio de la educación y la enseñanza e indagar sobre las miradas que se construyen acerca de los y las estudiantes cuando se elaboran explicaciones sobre el aprendizaje en torno al funcionamiento del cerebro y las implicancias epistemológicas y gnoseológicas de este tipo de razonamientos. De esta manera, coincidiendo una vez más con Terigi (2016) decimos que: 
(...) los procesos neurológicos sobre los que nos informan las investigaciones en neurociencias son condición necesaria, pero nunca suficiente, para comprender el aprendizaje o prescribir sobre la enseñanza. Desde la perspectiva de los especialistas en educación, se hace necesario sostener (una vez más) que el aprendizaje escolar no es un proceso ajeno a las condiciones de la escolarización, y que lo que está en discusión son justamente esas condiciones (p.59).

\section{Al decir de Bourdieu (1978) pensamos que:}

más que tratar de responder a la pregunta de manera científica, hay que tratar de hacer la ciencia de la pregunta misma; hay que tratar de analizar las condiciones de aparición de este tipo de interrogación y del racismo de clase que introduce (p.68).

En ese sentido, cabe preguntarse: ¿A qué se debe la difusión de este tipo de discurso de las neurociencias educacionales? ¿Qué demanda o necesidad de los propios docentes vienen a cubrir? ¿A qué se debe su exitosa recepción en los ámbitos educativos?

Asimismo, en relación a las cuestiones relativas a la diversidad también los discursos normalizadores que introducen elementos de la educación emocional y que interpelan a enseñar cómo regular las emociones para que las mismas sean productivas, remiten a la responsabilización del propio sujeto que aprende sobre su trayectoria educativa y social en general.

Uno de los propósitos de este escrito ha sido advertir sobre la reducción de la comprensión del aprendizaje humano al nivel de la actividad neural. Este enfoque reduccionista encuentra correlatos con la percepción meritocrática del éxito y fracaso escolar en tanto y en cuanto responsabiliza a los estudiantes del mismo al ensayar explicaciones descontextualizadas que no consideran las desigualdades que atraviesan a las trayectorias educativas de cada uno de aquellos. Cabe interrogarse entonces: ¿Es posible pensar la educación por fuera de su contexto y condiciones? ¿Estamos hablando de un sujeto que aprende sin historia personal ni colectiva?

En este sentido, en el análisis que hemos efectuado de los cursos de capacitación y formación dirigido a educadores (maestros y maestras, profesores y profesoras, entre otros) pudimos identificar propuestas que difunden ideas fijistas y biologicistas, discursos "erróneos" (lo que muchos de los propios neurocientíficos catalogan como "neuromitos") y enfoques reduccionistas que descontextualizan la situación de enseñanza y aprendizaje y el diseño de políticas públicas educativas.

En las propuestas analizadas se intersecan conocimientos del sentido común, pre-saberes de los docentes (propios de su formación y del ejercicio de la profesión) y resultados de los estudios de neurociencia básica. Se tensionan discursos más o menos tolerantes e inclusivos con afirmaciones que -basadas en "evidencia científica"- ofrecen herramientas para la resolución de problemáticas históricas y contemporáneas de los procesos de enseñanza y aprendizaje. Todo ello ocurre con el aval de la autoridad hegemónica, incuestionada e incuestionable del "saber científico", resulta en consecuencia pertinente 
Revista de la Escuela de Ciencias de la Educación. 2022, Año 18 1(17), 171188. Enero a junio. González, A. P. Discursos neuroeducacionales, diversidad y desigualdad: sobre la autoridad de la ciencia en ámbitos educativos.

recuperar y recordar (nos) aquí aquella idea de Bourdieu sobre aplicar a la ciencia misma y a los científicos una mirada vigilante sobre nuestras propias prácticas y el tipo de conocimiento que generamos $y$, fundamentalmente, si éste no coadyuva en el reforzamiento de relaciones de dominación a partir de las cuales la diversidad se transfigura en desigualdad.

\section{REFERENCIAS}

Battro, A. M. (2011). Neuroeducación: El cerebro en la escuela. En Lipina S. y Sigman M. (Eds.). La Pizarra de Babel: Puentes entre neurociencia, psicología y educación. El Zorzal.

Benarós S; Lipina SJ; Segretin M.S.; Hermida, M.J. y Colombo, J.A. (2010). Neurociencia y educación: hacia la construcción de puentes interactivos. Rev Neurol (50) 179-86.

Bertoni, L.A. (2007): La escuela y la formación de la nacionalidad, 1884-1890. En Bertoni, L.A. Patriotas, cosmopolitas y nacionalistas. La construcción de la nacionalidad argentina a fines del siglo XIX. Fondo de Cultura Económica.

Bourdieu, P. (1997). Capital cultural, escuela y espacio social. Siglo XXI.

Bourdieu, P. (1978). El racismo de la inteligencia. Intervención en el Coloquio del MRAP en mayo de 1978, publicada en Cahiers Droit et liberté (Races, sociétés et aptitudes: apports et limites de la science). 382, 67-71. Versión en español recuperada de http://sociologiageneral.sociales.uba.ar/files/2013/06/Pierre-Bourdieu-Elracismo-de-lainteligencia.pdf

Bourdieu, P. (2000). La dominación masculina. Anagrama.

Bowers, J. S. (2016). The Practical and Principled Problems With Educational neuroscience. Psychological Review, 123(5), 600-612.

Bruer, J. (1997). Education and the Brain: A Bridge Too Far. Educational Researcher, 26(8), 4-16.

Bruer, J. (2016). Neuroeducación: Un panorama desde el puente. Propuesta Educativa. 46, 14-25.

Carli, S. (2017). La educación pública como laboratorio social: neurociencias y espiritualidades empresariales. Recuperado de: https://conversacionesnecesarias.org/2017/07/03/la-educacionpublicacomo-laboratorio-social-neurociencias-y-espiritualidades-empresariales/

Castorina, J. A. (2016). La relación problemática entre neurociencia y educación. Condiciones y análisis crítico. Revista Propuesta educativa. 46, 26-41.

Dekker, S.; Lee, N.; Howard Jones, P. \& Jolles, J. (2012). Neuromyths in Education: Prevalence and Predictors of Misconceptions among Teachers. Frontiers in Psychology, 3(2), 415- 429.

De Vos, J. (2016). The Educated Brain: A Critique of Neuroeducation. De Vos, J. (Eds.), The Metamorphoses of the Brain-Neurologisation and its Discontents. Ghent: palgrave MacMillan.

Diez, M.; Novaro, G. y Martínez, L. V. (2017). Distinción, jerarquía e igualdad. Algunas claves para pensar la educación en contextos de migración y pobreza- Cuadernos del Instituto Nacional de Antropología y Pensamiento Latinoamericano, 26(2), 23-40. 
Duschatzky, S. y Skliar, C. (2000). La diversidad bajo sospecha. Reflexiones sobre los discursos de la diversidad y sus implicancias educativas, en Cuadernos de Pedagogía Rosario, Año IV (7), Centro de Estudios en Pedagogía Crítica.

Ferreres, A. \& Abusama, V. (2016). Neurociencias y educación. Paidós.

Foucault, M. (2004). El nacimiento de la clínica. Una arqueología de la mirada médica. Siglo XXI Editores.

Gagliano, F. (1991). Nacionalismo, educación y pluralismo cultural. Polémicas educativas en torno del Centenario. En A. Puigrós, Sociedad civil y Estado en los orígenes del sistema educativo argentino. Galerna.

INECO (19 de agosto 2019). Neurociencia y educación. La evidencia científica en el aula. [Posteo de curso sobre neurociencia y educación]. Facebook. https://www.facebook.com/INECOArgentina

Jordán, J. (1994). La escuela multicultural. Buenos Aires: Paidós.

Kaplan, C. (1997). La inteligencia escolarizada: un estudio de las representaciones sociales de los maestros sobre la inteligencia de los alumnos y su eficacia simbólica. Buenos Aires: Miño y Dávila.

Kaplan, C. (s/f). Papeles de coyuntura 2. Programa de Investigación Escolarización. Perspectivas históricas, pedagógicas y políticas de la educación. Instituto de Investigaciones en Humanidades y Ciencias Sociales, UNLP. Recuperado el 15 de octubre de 2020 de: http://idihcs.fahce.unlp.edu.ar/pephpp/wpcontent/uploads/sites/25/2019/10/2-papeles-de-coyuntura-emociones-yescuela.pdf

Lipina, S. (2016). Introducción. Actualizaciones en neurociencia educacional. Propuesta Educativa. 46, 6-13.

Manes, F. (2013). Introducción. En De Podesta, M. E. et. al. (comp.) El cerebro que aprende. Aique.

Marcus, G. (2013). The Problem with the Neuroscience Backlash. The New Yorker.

Recuperado de: http://www.newyorker.com/tech/elements/the-problem-withthe-neuroscience

Merlin, N. (2017). El feliz mundo neoliberal. Recuperado de: https://www.pagina12.com.ar/41342-el-feliz-mundo-neoliberal

OCDE (2007). La comprensión del cerebro. El nacimiento de una ciencia del aprendizaje. Ediciones Universidad Católica Silva Henríquez

Pallarés Domínguez, D. (2016). Neuroeducación en diálogo: neuromitos en el proceso de enseñanza-aprendizaje y en la educación moral. Pensamiento. 72(273), 941-958.

Raspall, L (2017) Neurociencia para educadores. Homo Sapiens.

Strauss, A., \& Corbin, J. (2002). Bases de la investigación cualitativa. Técnicas y procedimientos para desarrollar la teoría fundamentada. Editorial Universidad de Antioquía.

Tenti Fanfani, E. (2007). La escuela y la cuestión social. Ensayos de sociología de la educación. Siglo XXI.

Terigi, F. (2016). Sobre aprendizaje escolar y neurociencias. Propuesta Educativa. $46,50-64$. 